\title{
A Base Study on the Constancy Quality Control Test and Clause of Diagnosis Radiation Equipment
}

\author{
Yeji Heo*, Kyotae Kim ${ }^{* *}$, Sicheul Noh ${ }^{* * *}$, Sanghee Nam, Jikoon Park ${ }^{* * *}$ \\ Dept. of Biomedical Engineering, Inje University ${ }^{*}$,Dept. of Hybrid Medicine and Science, Inje University ${ }^{* *}$, \\ Dept. of Radiological Science, International University of Korea***

\section{진단용 방사선 발생장치의 수시 정도관리 항목 및 기준에 관한 기초 연구}

허예지*, 김교태**, 노시철***, 남상희*, 박지군***

인제대학교 의용공학과*, 인제대학교 융합의과학과 ${ }^{* *}$, 한국국제대학교 방사선학과 ${ }^{* * *}$

\begin{abstract}
Diagnostic radiation equipment diagnosis and treatment of disease of recent plays a central role, but this is based on the assumption of an appropriate balance of benefits and risks of diagnostic. If balance is not maintained has the potential to give an adverse effect on the health of the public. In the case of an overseas, the importance of (QA) quality assurance of medical equipment is growing, but evaluation criteria of quality assurance has not been clearly presented in domestic. Therefore, the modernization of medical equipment from the point at which the degree of cycle-by-cycle management system of foreign national to be suitable for diagnostic radiation generator entry and quality control standards by introducing a tailoring is necessary. In this study the most frequently used diagnostic radiation generator X-ray imaging apparatus of the general three-year periodic inspections at any time between the periodic inspection items and quality control methods and standards for the establishment of the United States, Canada and abroad, and international electronic literature search Technical Committee (International Electro-technical Commission, IEC) were compared with the provisions of item. Based on the national quality control items when opening frequent inspection items and standards presented as a basis for setting up study.
\end{abstract}

Key Words: Diagnostic radiation equipment, Quality control, International Electro-technical Committee

\section{요 야}

국내 진단용 방사선 발생장치는 3 년 주기로 시행되는 정기적인 정도관리 검사에 앞서 일별, 주별, 월별, 분기 반기 별로 시행하는 수시 정도 관리에 대한 항목 및 규정이 명확하게 지정되어 있지 않다. 미국과 유럽 등의 선진국에서는 정도 관리 항목에 대해 검사를 수행하는 검사자를 구분하여 국가 기관에 보고하도록 되어 있으므로 체계적인 검사 수 행과 더불어 검토가 가능하다. 그러므로 의료 장비의 현대화가 이루어지는 시점에서 국외의 주기별 정도관리 시스템을 국내 진단용 방사선 발생 장치에 적합하도록 도입하여 정도관리 항목과 기준의 재정립이 반드시 필요하다. 이에 본 논 
문에서는 진단용 방사선 발생장치 중 가장 빈번히 사용되고 있는 일반 $\mathrm{X}$ 선 촬영 장치의 3 년 정기점검 사이에 주기적인 수시 정도 관리 검사 항목과 방법 및 기준 수립을 위해 미국, 캐나다 등의 국외 문헌 조사 및 국제 전자 기술 위원회 (International Electro-technical Commission, IEC)의 규정 항목과 비교하였다. 이를 바탕으로 국내 수시 정도관리 항 목 신설 시 필요한 검사 항목 및 기준 설정을 위한 기초 자료로 제시하고자 하였다.

중심단어: 진단용 방사선 발생 장치, 품질 관리, 국제 전기기술 위원회

\section{I. 서 론}

최근 현대 의학적 진단 도구로써 방사선 진단 장비 는 환자 진료에 있어 유용하게 사용되고 있으며 정확 한 진단 및 질병의 조기 발견을 위해 검사 빈도 또한 점차 높아지고 있는 추세이다. 이러한 진단 장비를 이 용 시 진단에 필요한 이득과 손실을 적절하게 균형을 유지하여야 하며, 이때 발생하는 손실 중 일부인 환자 의 불필요한 선량을 최대한 줄여야 한다 ${ }^{[1]}$. 그러므로 국외의 의료기기에 대한 품질 보증의 경우 이러한 문 제점을 최소화하기 위하여 그 중요성이 대두되고 있 으며 국제 전기 기술 위원회(International Electrotechnical Commission, IEC)에서는 체계화된 규제 방안 을 주기적으로 보완하여 개정판을 배포하고 있다 ${ }^{[2]}$. 국내 의료기기는 의료기기법에 따라 식품의약 안정처 의 품목 허가를 받거나 신고를 통해 새로운 장비에 대 한 사전검사를 통해 장비의 안전성을 평가받으며, 의 료법 37조에 따라 해당 진단용 방사선 발생장치는 해 당 검사 기관을 거쳐 안전관리규칙에 따라 식품 의약 품 안전 관리처에 등록된 검사기관이 3년 주기의 정기 적인 사후 검사를 통해 안전관리 체계를 구축하고 있 다 ${ }^{[3]} .3$ 년 주기로 이루어지는 안전관리는 장비 자체의 안전성에 관한 내용을 포함하고 있으며 이는 일반 진 단용 방사선 발생 장치 영상의 질 관리를 위한 목적으 로 시행되고 있다. 하지만 국내 진단용 방사선 발생장 치는 3 년 주기로 시행되는 정기적인 정도관리 검사에 앞서 일별, 주별, 월별, 분기 반기별로 시행하는 수시 정도 관리에 대한 항목과 검사 기준 등에 대해서 법적 으로 제정되어 있지 않은 실정이다. 이는 미국 및 캐 나다, 유럽 등 외국에서 법적으로 시행하고 있는 정도 관리 체계 및 보수, 유지하는 수준에 비하여 매우 미 흡함을 보이고 있으며, 의료 장비의 현대화가 이루어 지는 시점에서 수시 정도관리의 검사 항목 및 내용 수 정을 통해 정도관리의 재정립이 반드시 필요하다 ${ }^{[1],[4]}$.
또한 미국과 유럽 등의 선진국에서는 정도 관리 항목 에 대해 검사를 수행하는 검사자를 구분하여 정도관 리를 시행한 후 국가 기관에 보고하는 체계를 갖추고 있으므로 체계적인 검사 수행과 보고가 가능하도록 국가적인 지원을 강화하고 있다. 이러한 체계적인 정 도관리 검사를 통해 진단용 방사선 발생장치의 사용 시 영상의 화질 향상 및 사용하고자 하는 기기의 정확 성을 높임으로써 환자의 불필요한 피폭선량의 저감화 가 가능하다. 따라서 국내의 검가 기관에서도 3 년 이 하에 시행하는 정도 관리 검사의 항목에 대해서 국가 적인 규제 및 관리를 시행하여 체계적인 정도관리 검 사가 가능하도록 하여야 하며 장치 사용자가 정도 관 리를 수행하기 곤란한 전기적 안전 점검, 기계적 점검 및 안전 예방 확대 등에 대해서는 외부에 위탁하거나 제조사와 장비를 사용하는 실무진이 서로 연대하여 장치를 잘 유지할 수 있도록 하여 의료의 질 향상에 노력하여야 한다. 이에 본 논문에서는 진단용 방사선 발생장치 중 가장 빈번히 사용되고 있는 일반 $\mathrm{X}$ 선 촬 영 장치의 3 년 정기점검 사이에 주기적인 수시 정도 관리 검사 항목과 방법 및 기준 수립을 위해 미국, 캐 나다 등의 국외 문헌 조사 및 국제 전기 기술 위원회 의 규정 항목과 비교하였다. 이를 바탕으로 하여 국내 수시 정도관리의 항목과 방법 및 기준 제정 시 기초 자료로써 제시하고자 하였다.

\section{II. 연구방법}

\section{1. 국제기관 정도관리 문헌 조사}

국제 전자 기술 위원회에서는 IEC Publication을 통 해 정도관리 항목 및 기준에 대한 규정을 제시하고 있 으며, 이러한 규정은 유럽을 포함한 국외 각국에서 채 택하고 있는 권고 사항이다 ${ }^{[5]}$. 따라서 본 논문에서는 특수 의료 장비를 제외한 일반 진단용 방사선 발생장 치 중 일반 $\mathrm{X}$ 선 촬영 장치에 적용되는 정도관리 검사 
항목 및 기준을 조사하기 위하여 국제 전자 기술 위원 회에서 규정하는 IEC 61223-2-11의 "Evaluation and routine testing in medical imaging departments - Part 2-11: Constancy tests - Equipment for general direct radiography"의 규정에 대한 문헌을 조사하였다 ${ }^{[6]}$.

\section{2. 국가별 정도관리 문헌 조사}

국외 진단용 방사선 발생장치는 미국 및 캐나다에 서 규정하고 있는 정도 관리 항목 및 기준에 대하여 문헌 조사를 시행하였다. 미국의 진단용 방사선 발생 장치 정도관리 항목 및 기준은 $21 \mathrm{CFR}$, 미국 의학물리 학회(American Association of Physicists in Medicine, $\mathrm{AAPM}$, New Jersey의 문헌 자료를 조사하였다. 그리고 캐나다의 진단용 방사선 발생장치 정도관리 항목은 $\mathrm{BC}$ 방역센터(BC Centre for Disease Control, BCCDC), Cancer care Manitoba 등의 문헌을 조사하였다. 이러한 문헌 조사를 바탕으로 하여 IEC 61223-2-11 규격과 미 국 및 캐나다의 정도관리 항목을 비교하여 공통적으 로 시행하고 있는 일관성 정도관리 검사에 대해 비교 분석 하였다.

\section{III. 결 과}

\section{1. 국제기관의 평가 항목 및 기준}

Table 1. Evaluation and routine testing in medical imaging departments - Part 2-11: Constancy tests - Equipment for general direct radiography

\begin{tabular}{|c|c|}
\hline 평가 항목 & 기준 \\
\hline $\begin{array}{r}\text { X선원 장치의 } \\
\text { 방사선 출력 }\end{array}$ & $\begin{array}{l}\text { 1. 수동 상태에서의 시험 } \\
- \pm 20 \% \text { 이내 } \\
\text { 2. 자동 노출 제어 상태 } \\
\text { - PMMA, 알루미늄과 같은 재료일 경우 } \\
\quad+25 \%,-20 \% \text { 범위 }\end{array}$ \\
\hline $\begin{array}{l}\text { 수상구역의 } \\
\text { 방사선 입력 }\end{array}$ & $\begin{array}{l}\text { 1. 수동 제어상태에서의 시험 } \\
\text { - 광학 농도 기준선 값의 } \pm 0.3 \\
\text { 2. 자동 노출 제어 상태에서의 시험 } \\
\text { - 광학 농도는 기준선 값이 } \pm 0.15 \text { 이내 }\end{array}$ \\
\hline
\end{tabular}

\begin{tabular}{cc}
\hline & 1. 초점 수상기 간 지시 거리 \\
& $- \pm 1 \%$ 이내, 초기 일관성 시험 측정 거리의 \\
& $\pm 1 \%$ 이내가 되어야 함 \\
& 2. 선 수상기에 대한 방사선 빔 축의 수직 위치 \\
& - 방사선 빔 축은 수상 구역에 대한 \\
& 수직축의 1.5 도 이내 \\
& 3. 방사선 조사야 크기의 수치적 지시 정확도 \\
기하학적 특성 & - 방사선 조사야 크기의 지시된 치수와 \\
& 측정된 치수 사이의 차이는 초점 수상기 \\
& 간 거리의 $\pm 2 \%$ 이내에 있어야 한다.
\end{tabular}

문헌 조사 결과, 평가 항목은 5 가지로 장치의 성능 에 관련된 항목이 3 가지, 영상 품질에 관련된 항목이 2 가지로 구분된다. 장치의 성능에 관련된 항목은 X-ray 장치에 방사선 출력 및 정확성에 대한 항목으로 출력 은 $\mathrm{AEC}$ 의 유무에 따라 기준이 상이하다. 정확성은 초 점 수상기 간 거리(Source to Image Distance, SID) 및 방사선 빔 축 그리고 조사야 크기에 대하여 평가함으 로써 방사선 조사 시 정확성을 확인하고 있다. 또한 영상 품질에 관련된 항목은 광학적 농도 및 해상도에 대한 항목으로, 광학적 농도는 농도차이에 대하여 관 리하고 있고, 해상도는 테스트 패턴을 이용하여 관리 하고 있다.

\section{2. 국가별 평가 항목 및 기준}

미국의 정도관리 검사는 1968년에 제정된 Radiation Control Health and Safety Act에 의해 시작 되었으며 현 재는 의료기기 방사선 보건 센터에서 관리하고 있다. 의료기기 방사선 보건 센터는 진단용 방사선 발상들 이 사용에 따른 장래의 정보 수집과 이들 제품에 대한 품질보증 및 비 연방규정 $21 \mathrm{CFR}$ 을 제정하여 제조업 체에서 자사 제품과 의료기관에 각각 연 1 회 검사하여 그 결과를 $\mathrm{FDA}$ 에 보고하는 체계를 갖추고 있다. 또한 정부에 의한 정도관리보다는 민간이 주도하는 정도관 리가 주를 이루고 있으며 병원신임위원회(Joint Commission on Accrediation of Healthcare Organization, $\mathrm{JCAHO}$ ), 미국 의학물리학회, 미국 방사선과(American Collage of Radiology, ACR)등이 중심이 되어 방사선 기 
기 및 의료 장비의 정도관리를 철저히 시행하고 있다. 이렇듯 체계적인 정도관리 시스템을 통해 최적의 영 상 품질과 안전한 작업 환경을 일관성 있게 유지하고 있으며, 뿐만 아니라 합리적인 비용으로 민간기관 주 도의 정도관리 검사를 시행하고 있다. Table 2는 미국 에서 시행하고 있는 주기별 정도관리 항목과 기준으 로 체계화된 검사 기준을 제시하고 있다.

캐나다의 진단용 방사선 발생 장치의 사용은 매년 약 20 만 건 이상이며 검사 받는 수검자의 보호를 위해 캐나다 연방 및 지방 정부 기관에서 입법 제정을 통한 진단용 방사선 발생장치의 안전한 설치 및 안전에 관 한 노력과 조치를 기울이고 있다 ${ }^{[7]}$. 그리고 대부분의 지방과 연방 정부 기관의 진단용 방사선 발생 장치 시
설의 영상 품질을 제어하는 기본적인 정도 관리 프로 그램에서 제안하는 요구 사항을 규정하고 있으며 이 는 정도관리 위원회에서 결정하게 된다. 진단용 방사 선 발생장치의 1 년 미만 정도관리 검사의 경우 기술자 와 의학물리학자를 중심으로 하여 매일, 매주, 매월, 분기별로 정도 관리 검사를 시행하고 있담] 또한 연 간 시행하는 정도관리 항목은 방사선 안전 관리자 및 의학 물리학자, 교수에 의해 검사를 수행하여 세분화 된 검사 체계를 이루고 있으며 검사에 대한 정확성을 위해 품질 관련 위원회를 통해 절차 및 결과를 검증하 고 있다 ${ }^{[9]}$. Table 3 는 캐나다의 주기별 정도관리 항목 및 기준이다.

Table 2. Cycle-by-cycle assessment items and criteria of United State

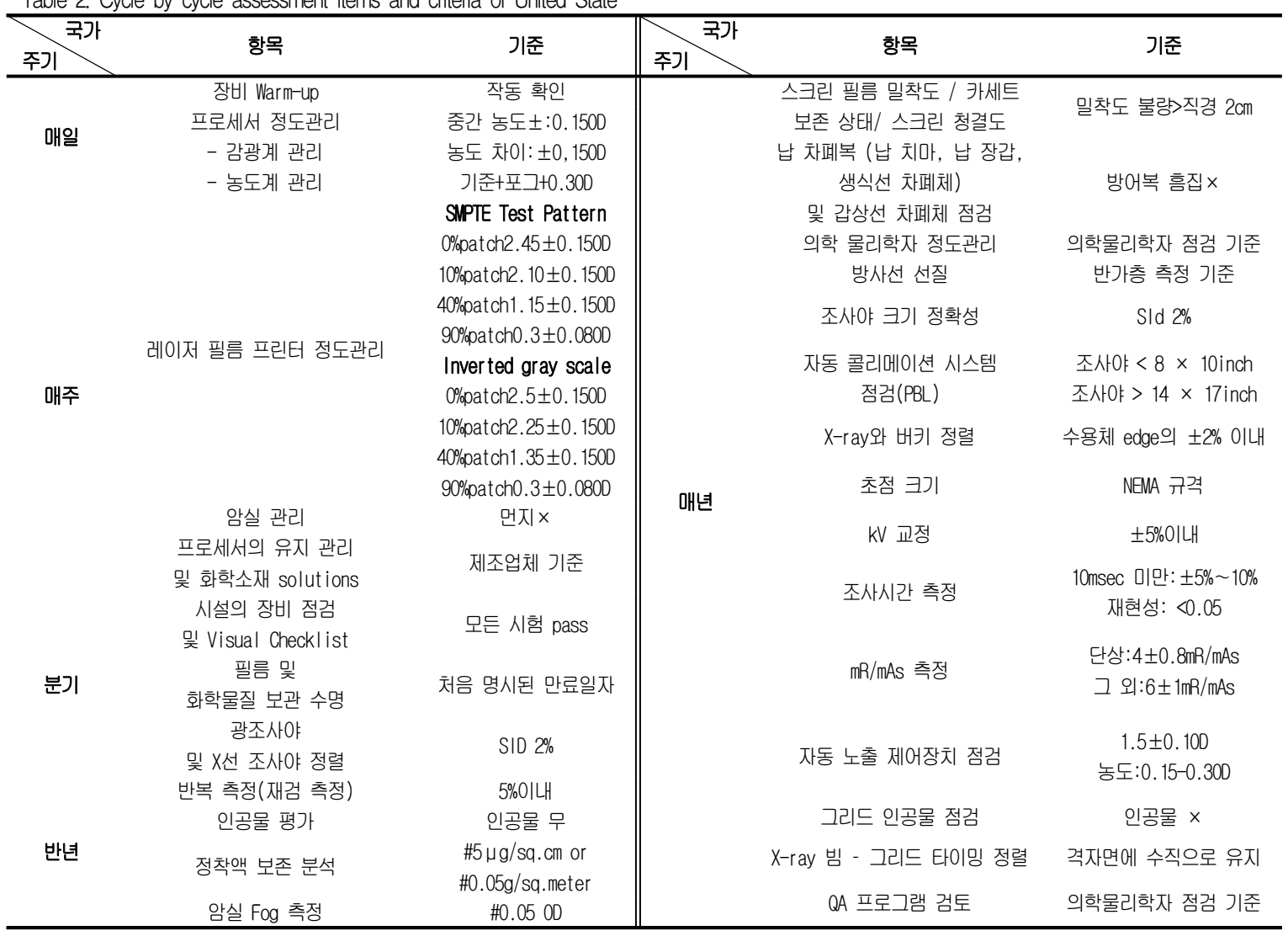


Table 3. Cycle-by-cycle assessment items and criteria of Canada

\begin{tabular}{|c|c|c|c|c|c|}
\hline 주기 국가 & 항목 & 기준 & 주기 국가 & 항목 & 기준 \\
\hline \multirow{3}{*}{ 매일 } & \multirow[t]{2}{*}{ 육안 검사 } & $\begin{array}{c}\text { 케이블, 인터록, 모서리, 환자 } \\
\text { 안전 등의 육안 확인 검사 }\end{array}$ & \multirow{11}{*}{ 매년 } & $\begin{array}{l}\text { 반가층 } \\
\mathrm{mAs}\end{array}$ & $\begin{array}{c}\geq 2.3 \mathrm{~mm} \mathrm{Al} \\
\text { 설정 값의 } \pm 10 \%+2 \mathrm{mAs}\end{array}$ \\
\hline & & 프로그래밍 & & 조사야 크기 지표 & SID의 $2 \%$ 이내 \\
\hline & 기능 점검 & $\begin{array}{c}\text { 프로토콜 엑세스 } \\
\text { 및 장비의 켜짐 확인 }\end{array}$ & & 초점 크기 점검 & $\pm 50 \%$ \\
\hline 매주 & 대조도 관련 & 영상 세부사항 기록 & & X-ray Beam과 버키 정렬 & SID의 $2 \%$ 이내 \\
\hline 매수 & $\begin{array}{c}\text { 세부사항 점검 } \\
\text { X-rav 서직 밈 버키 }\end{array}$ & 최소한의 대조도비가 관찰되야 함 & & kV 교정 및 kV 파형 점검 & 지정된 $\mathrm{kVp}$ 값의 $\leq 5 \%$ \\
\hline \multirow{3}{*}{ 분기 } & 정렬 확인 & 수용체 edge의 $\pm 2 \%$ 이내 & & 출력 선형성 & $X_{1}-X_{2} \leq 0.1\left(X_{1}+X_{2}\right)$ \\
\hline & X-ray/광조사야 정렬 & SID의 $2 \%$ 이내 & & 조사시간 정확도 & $\pm 10 \%+1 \mathrm{~ms}$ \\
\hline & 조사야 밝기 교정 & $100 \mid x(S \mid D$ 1m 또는 최대 높이) & & 선질 점검 & 평균 값의 $\pm 15 \%$ 이내 \\
\hline \multirow{3}{*}{ 반기 } & $\begin{array}{c}\text { 자동 노출 제어장치 } \\
\text { 변화 }\end{array}$ & $\begin{array}{c}\mathrm{kVp} \text { 변화시 } \pm 0.1500 \\
\mathrm{kVp} \text { 고정, 두께 변화시 } \pm 0.200 \\
\mathrm{kVp} \text {, 두께 고정시 } \pm 0.100\end{array}$ & & \multirow{3}{*}{$\begin{array}{c}\text { X-ray 빔 - 그리드 타이밍 } \\
\text { 정렬 }\end{array}$} & $\begin{array}{c}\leq 0.05 \\
\text { 평균값의 } \pm 15 \% \text { 이내 } \\
\text { 진단에 영향이 없도록 유지 }\end{array}$ \\
\hline & 기계적 안전성 & $\begin{array}{l}\text { X선관이 안정되게 고정 } \\
\text { 작동시 tube의 진동 } \times\end{array}$ & & & \multirow[t]{2}{*}{ 격자면에 수직으로 유지 } \\
\hline & 필름 농도 & 기준점의 \pm 0.300 & & & \\
\hline
\end{tabular}

\section{IEC 규격과 국외 정도관리 항목 비교}

국내외 문헌 조사를 바탕으로 IEC 규정에서 제시하 는 정도관리 항목을 비교하였고, 그 결과를 Table 4에 나타내었다.

Table 4. IEC standard and Abroad Quality Assurance

국가
선원 장치의 방사선 출력
수상구역의 방사선 입력
$\begin{gathered}\text { 기하학적 특성 } \\ \text {-방사선 조사야 크기 } \\ \text {-초점 수상기간 지시치 거리 } \\ \text { X선 영상 전체에 걸친 } \\ \text { 광학 농도 변화 } \\ \text { 고 대비 세부 묘사의 해상도 }\end{gathered}$
분기 / 매년

비교 결과, 고 대비 세부 묘사의 해상도 항목은 미 국 과 캐나다 모두 검사를 수행하고 있지 않고 있으며, $\mathrm{X}$ 선원 장치의 방사선 출력에 관한 항목은 미국에서
시행하지 않고 있으나, 캐나다에서는 매년 검사 항목 으로써 수행하고 있는 것으로 파악되었다. 이러한 항 목을 제외한 나머지 항목에 대해서는 미국과 캐나다 모두 분기별 또는 연간 시행하고 있는 항목으로 확인 되었다.

\section{$\mathrm{IV}$. 결론 및 고찰}

진단용 방사선 발생 장치가 의료 기관에서 환자의 진료 목적으로 사용하기 위해 설치되어가는 증가 추 세는 1950 년 6.25 중 국 의료기관에서부터 민간 의료기 관까지 급속한 증가를 보였으며 특히 1977년 7월부터 시행한 국민 의료보험의 실시에 따라 의료 기관에 빠 르게 진단용 방사선 발생장치가 설치되어졌다 ${ }^{[10]}$. 이러 한 방사선 발생 장치의 증가와 더불어 1994년 신설된 의료법 제 32조에 따라 진단용 방사선 발생장치를 새 로 설치하거나 이전 설치시는 사용하기 전에 관할 시 장. 군수, 구청장에게 신고하고 식품의약품 안전 평가 원에 등록된 검사 기관의 검사를 시행하여 진단용 방 사선 발생장치에 대한 안전 관리 체계를 구축하고 있 다. 하지만 국내의 일반 진단용 방사선 발생장치의 발 전이 2000년대 이후로 급격히 디지털화 장비로 보급되 
고 있음에도 불구하고 정도관리 항목과 기준은 별다 른 개정 없으며 1 년 미만으로 시행하는 일관성 검사 주기별 검사 항목 및 기준에 관한 규정이 없고, 3 년마 다 시행하는 정기적인 안전 관리 검사에 관해서만 시 행되고 있다. IEC에서 제시하는 국제 표준은 모든 국 가의 전기 기술위원회들로 구성된 범세계적 표준화 기구이며 전기 전자 및 정보 분유에 대한 국제 규격을 제정 시 분야별로 발행번호를 지정하여 공표하고 있 다. 한편 수시 정도관리 검사 항목과 기준이 정립화 되어 있지 않은 국내의 정도관리 검사와는 달리 미국 과 캐나다는 정도 관리 항목에 대한 주기, 검사 기준 과 방법, 검사자를 명확히 구분하여 체계적인 정도관 리 검사가 시행되도록 정부에서 관리하고 있다. 미국 은 디지털 장비, 아날로그 장비를 구분하여 정도관리 항목과 기준을 설정하고 방사선사와 의학물리학자가 시행하는 항목을 정확하게 구분하여 병원 자체적으로 시행할 수 있도록 규정하고 있다. 또한 캐나다의 경우 도 일별, 분기별 연간 시행하는 정도관리 검사를 의학 물리학자 및 기술자, 교수를 중심으로 하여 주기적 시 행하도록 규정하고 있다. 따라서 진단용 방사선 발생 장치 중 가장 빈번히 사용되고 있는 일반 $\mathrm{X}$ 선 촬영 장 치 또한 3 년 주기의 안전에 관한 정도관리 검사를 위 해 방사선 발생 장치 도입 이후에 방사선 발생 장치를 사용하는 실무자 또는 관계자들이 주기적인 보수 점 검을 통해 의료 기기의 안정성을 확보 하고, 성능과 품질 유지, 고장을 미연에 방지하여 일상적인 점검과 함께 성능 유지 점검을 이용한 수시 정도관리를 시행 하는 것이 좋을 것으로 판단된다. 또한 수시 정도관리 의 주기와 항목, 기준, 검사 방법 등을 디지털, 아날로 그 장비에 적합하도록 구분하여야 하며 검사를 시행 하는 실무자 및 관리자의 분담 업무 및 데이터 평가에 대한 명확한 기준 값과 평가 방법을 규정하여야 할 것 으로 사료된다. 그리고 IEC에서 규정하는 수시 정도관 리 검사 항목 및 기준을 고려하여 이를 수용하고, 국 내 수시 정도 관리 항목으로 적합한 국외 정도관리 항 목을 수용하여 국내 수시 정도관리 평가에 적용 가능 하도록 새로운 표준안을 마련하여야 하여야 하며 이 는 국제적인 기준에 부합하는 자가 점검 항목과 시험 방법으로 점검 결과를 검사 기관의 정기 검사 결과와 함께 정부에 보고할 수 있는 제도적 근거를 제시할 필
요성이 있을 것으로 사료된다.

\section{참고문헌}

[1] Kyo Tae Kim, et al., "A Study on the Improvement of Evaluation Methods and Standards for Simulation evaluation of Computed Tomography", The Korean Society of Radiology, Vol 7, No 5, pp. 339 - 345, 2013.

[2] Korea Testing Laboratory, "A study on the mandatory application plan for the third edition of IEC 60601 standards series(General Standard, Collateral Standards, Particular Standards)", National Institute of Food and Drug Safety Evaluation, 2011.

[3] Safety management of Diagnostic radiation generator rules, Inspection criteria for diagnosis of radiation devices-Article, Vol. 4, No. 1, Medical law Article 37.

[4] Sang Won Jo, Seon Hyeong Choi, etc, "A study on the improvement of safety testing standards and methods for mammpgraphy", Original Article, J Korean Soc radiol., Vol. 67, No. 6, pp. 451-459, 2012.

[5] Choi In Seok, Kim jyung Min, etc, "The recent trend of the national and international standard of manufacturing quality control for diagnostic X-ray equipment", Radiation Technology and Science, Vol. 32, No. 1, 2009.

[6] Agency for Technology and Knowledge Economy, "Evaluation and routine testing in medical imaging departments - Part 2-11: Constancy tests - Equipment for general direct radiography", 2005.

[7] 21 CFR 1030 : Performance standards for microwave and radiation frequency emitting products.

[8] "Diagnostic X-ray Unit QC Standards In BC", Radiation Protdction Services, 2004.

[9] "Quality Assurance in Diagnostic Radiology - Report of the Sub - Committee on Standards to Radiation Protection Setvice", John Aldrich, 2000.

[10] Devision of radiation safety and medical products, "A study on guidance for test and method of medical radiation", Food and Drug Administration, 2011. 